\title{
Proceeding
}

Supplementary Issue: Summer Conferences of Sports Science. Costa Blanca Sports Science Events, 20-21 September 2019. Alicante, Spain.

\section{Favourite music as an increasing factor of the result in the control running of athletes}

\author{
ROMAN SERGEEVICH NAGOVITSYN ${ }^{1}$, FANAVI HAYBRAHMANOVICH ZEKRIN², TATYANA VLADIMIROVNA \\ FENDEL'3 ${ }^{3}$ DMITRY ALEXANDROVICH ZUBKOV4, ALEKSANDER YURIEVICH OSIPOV5 \\ ${ }^{1}$ Department of Physical Culture and Life Safety, Glazov State Pedagogical University, Russian Federation \\ ${ }^{2}$ Department of Theory and Methods of Martial Arts, Tchaikovsky State Institute of Physical Culture, Russian \\ Federation \\ ${ }^{3}$ Department of Tourism and Management, Tchaikovsky State Institute of Physical Culture, Russian Federation \\ ${ }^{4}$ Department of Social, Humanitarian, Pedagogical and Natural Sciences, Tchaikovsky State Institute of Physical \\ Culture, Russian Federation \\ ${ }^{5}$ Department of Physical Culture, Siberian Federal University, Krasnoyarsk State Medical University named after \\ professor V.F. Voyno-Yasenetsky, Siberian Law Institute of the Ministry of Internal Affair of Russia, Russian Federation
}

\begin{abstract}
Background: Musical accompaniment of the implementation of physical exercises is interconnected with the motor activity of a person, which, as an art, can act through psychology and physiology to increase the athlete's result. The aim of the study was to analyse the influence of listening to your favourite music while running athletes of various qualifications at medium distances to increase the result in the control test. Study participants: athletes (14-18 years old): professional athletes involved in the athletics section "Athletics" ( $n=28)$, and amateur athletes engaged in other sports sections or not involved in sports sections at all $(n=28)$. During the control test at medium distances, the athletes of the experimental group used special musical accompaniment. The results of the study. The implementation of a systematic training process in running and the use of special musical accompaniment when fulfilling the author's conditions for its implementation during the control testing are significantly more effective $(p<0.05)$. To a greater extent, to increase the result of athletes using musical accompaniment during the training process, and amateur athletes in the control test 2000 and 3000 meters $(p<0.05)$, especially in the last third of the passage of the control distance. Findings. The practical significance and novelty of the work lies in the fact that the efficiency of playing music while running will be effective in the control test, if the author's development stated in the study is clearly taken into account. Keywords: Favourite music; Running; Middle distances; Testing.
\end{abstract}

\section{Cite this article as:}

Nagovitsyn, R.S., Zekrin, F.H., Fendel', T.V., Zubkov, D.A., \& Osipov, A.Y. (2019). Favourite music as an increasing factor of the result in the control running of athletes. Journal of Human Sport and Exercise, 14(5proc), S1829S1841. doi:https://doi.org/10.14198/ihse.2019.14.Proc5.02

Corresponding author. Department of Physical Culture and Life Safety, Glazov State Pedagogical University, Russian Federation. http://orcid.org/0000-0003-4471-0875

E-mail: gto18@mail.ru

Supplementary Issue: Summer Conferences of Sports Science. Costa Blanca Sports Science Events, 20-21 September 2019. Alicante, Spain.

JOURNAL OF HUMAN SPORT \& EXERCISE ISSN 1988-5202

(c) Faculty of Education. University of Alicante

doi:10.14198/jhse.2019.14.Proc5.02 


\section{INTRODUCTION}

To date, theoretical and methodological studies in the field of physical culture and healthy lifestyles of the population are focused on the search for non-traditional forms of increasing the effectiveness of physical education activities. Innovative technology in this direction is the idea of using music to increase athletic performance (Karageorghis, 2014). Musical accompaniment of the implementation of physical exercises is one of those areas that is interconnected with a person's physical activity, which, as an art, can influence physical activity through psychology and physiology (Thaut et al. 1999; Atan, 2013).

The beneficial effect of using music in sports and physical exercises has a long history and strong intuitive appeal (Terry \& Karageorghis, 2006). As a rule, music in physical education and sports is not used significantly, with the exception of sports that must be rhythmized to be joint motor activities or sports groups, such as aerobics or group fitness (Matesic \& Cromartie, 2002). However, with the rapid development of technology in all spheres of human life, listening to any music has become very convenient, mobile and portable (Nagovitsyn et al. 2015). There was an explosion in the use of music by athletes during training and competition. Countless millions of amateur athletes have begun to use music to improve the quality of everyday workouts. At the touch of a button or voice command, it became possible to compose any music playlists to satisfy any individual musical addictions (Karageorghis, 2014).

Today, many scientific studies show that music has a positive effect on the training process, the nervous system and relaxation (Ghobadi, 2018; Kozina et al., 2018). Music has the ability to capture attention, uplift, generate emotions, change or regulate mood (Lane et al., 2011). As well as evoke memories, increase labour productivity, reduce restrictions and stimulate rhythmic movements - all this has potential applications in sports and in general in physical exercises (Atan, 2013). It is scientifically proved that music has a positive effect on the implementation of running, as an aid to the psycho-physiological processes that occur in athletes with the onset of fatigue and various types of exercise (Dyrlund \& Wininger, 2008; Yamashita et al., 2006). What exactly is the results on physical quality - endurance, in comparison with other qualities, musical accompaniment is the most effective means (Ghobadi, 2018).

Scientific developments in this direction have focused on the study of the synchronism and asynchrony of musical accompaniment and the passage of distance in running (Karageorghis, 2016; Karageorghis \& Jones, 2000). Experimental studies on the influence of music on psychological processes, physiological activity in the athlete's body (Karageorghis, 2014). Scientists began comparative studies to identify the effectiveness of different types of musical accompaniment for the implementation of motor actions (Matesic \& Cromartie, 2002; Lanzillo et al., 2001; Potteiger et al., 2000). How does it affect the loads of minimum, moderate or maximum load in aerobic and anaerobic sports (Karageorghis, 2016; Jarraya et al., 2012). Which groups of students, by gender and age (Anshel \& Marisi, 2013), in terms of physical activity, fitness and sports qualifications from beginners to professionals (Baldari et al., 2010), are more influenced by music (Bigliassi et al., 2019; Mohammadzadeh et al., 2008). At what stage of the passage of the distance do significant changes occur in the athlete's body when performing physical activity with music (Copeland \& Franks, 1991; Lima-Silva et al., 2012).

Despite all the positive aspects of using music, at the moment, discussions are continuing about whether to allow participants in running competitions to use personal listening devices. Mobile devices are considered to pose a security risk, as runners are said to be so busy listening to music that they could compromise safety and cause injury to their rivals or themselves. Various international amateur athletics federations are trying 
to busily limit the use of personal devices in amateur competitions, as they are strictly forbidden at high-level official sports competitions (Karageorghis, 2014).

In connection with this, the object of our study was to study the effect of the use of music in quiz testing and the training process of athletes in athletics on medium distances. Despite the versatile theoretical and experimental elaboration of the identified direction, the question of the selection and conditions for providing musical accompaniment in the control testing of students of different sexes and the level of physical development at medium distances is not well understood.

The aim of this study was to analyse the influence of listening to your favourite music while running athletes of various qualifications at medium distances to increase the result in the control test.

\section{MATERIAL AND METHODS}

\section{Participants}

The study participants were schoolchildren (14-18 years old). All participants in the study at least 3 times a week are actively engaged in physical exercises and have no contraindications to maximum aerobic exercise. The group of study participants included: professional athletes involved in the athletics section "Athletics" $(n=28)$, and amateur athletes engaged in other sports sections or not involved in sports sections at all $(n=28)$. Each of these groups was divided into two equal parts by gender (boys and girls), and by using musical accompaniment during the training process (using and not using musical accompaniment during the training process).

\section{Research methods}

Participants wished to take part in an experiment to improve their physical fitness to meet the presidential testing standards "Ready for Labor and Defense" (Nagovitsyn et al., 2018). During the execution, all participants in the study were invited to use any musical accompaniment using mobile devices when passing the distance. It should be noted that this was not a prerequisite for the implementation of the experiment for both groups. Portable gadgets with music should not "hamper" motor actions while running, and also not to violate safety precautions on dimensionless and unregulated treadmills.

\section{Organization of the study}

The experiment was implemented on the basis of the Children's Youth Sports School in Glazov, the Udmurt Republic, Russia. All participants in the study implemented a training process to develop endurance by means of implementing medium and long distances for 6 months at least 3 times a week in a specialized stadium and non-special running tracks. Prior to the experiment, preliminary testing was implemented, in which all respondents to the study participated. After the experiment, after 6 months of the training process, a final control test was implemented, and then two weeks later the closing test was carried out to "clean" identify the effectiveness of the study.

During the final control testing, the participants of the experimental and control groups used special musical accompaniment while running at medium distances (2000 and 3000 meters). It included listening to favourite for each participant in the experiment music tracks in a portable gadget, mainly wireless connection with headphones via Bluetooth. The selection of music was carried out exactly 1 month before the control test and consisted of 4-5 favourite music tracks or motivating for physical exercises, regardless of the genre, which were offered individually by each participant. The peculiarity of the author's condition in the implementation of music was that the respondents should not, after selecting their favourite music before the 
control test, which consisted of the 1st month, generally listen to these tracks not during training, not outside the training process. This condition was created to increase a reliable positive emotional effect during control tests in middle distance running. Respondents who did not fulfil this condition were excluded from the study and their results were not calculated in the average results for the experimental sample. Before the start of physical testing, a specially prepared (1 month ago) playlist was loaded into the participant's gadget and then listened to when it passed the control distance.

To determine the level of performance at medium distances (girls - 2000 meters, boys - 3000 meters), we used the indicators of the presidential testing standards - the All-Russian physical culture and sports complex "Ready for Labor and Defense". When overcoming the distance, the participants in the control test recorded intermediate results in the distance: for male participants at 1000, 2000 and 3000 meters; in female subjects at marks of 650, 1300 and 2000 meters. Preliminary to the experiment and closing control testing two weeks after the implementation of the final test in middle-distance running was not accompanied by the introduction of the author's development during the passage of the athletics distance by all participants in the experiment.

\section{Statistical analysis}

Processing the results of the study was carried out using the statistical program SPSS20. The significance of differences in the results was determined using Student's T-test at $p<0.05$. Mathematical and statistical processing was carried out between the average indicators of the control and experimental groups for each category of athletes in the preliminary, final and final control tests. Moreover, in the final testing, we additionally analysed the results of athletes covering the distance in each of the three test segments.

\section{RESULTS}

Table 1. Results of control testing of athletes using musical accompaniment during the training process.

\begin{tabular}{|c|c|c|c|c|c|c|c|c|c|c|c|c|}
\hline \multirow[b]{2}{*}{ Group } & \multicolumn{2}{|c|}{$\begin{array}{c}\text { Preliminary } \\
\text { testing }\end{array}$} & \multicolumn{7}{|c|}{ Final testing } & \multicolumn{3}{|c|}{ Closing testing } \\
\hline & $\begin{array}{c}3000 \\
m\end{array}$ & $P$ & $\begin{array}{c}3000 \\
m\end{array}$ & $\mathrm{P}$ & $\begin{array}{c}0- \\
1000 \\
m\end{array}$ & $\mathrm{P}$ & $\begin{array}{c}1000- \\
2000 m\end{array}$ & $P$ & $\begin{array}{l}2000- \\
3000 \mathrm{~m}\end{array}$ & $P$ & $\begin{array}{c}3000 \\
m\end{array}$ & $P$ \\
\hline \multicolumn{13}{|c|}{ Boys - professional athletes (3000 meters) } \\
\hline $\begin{array}{l}E G \\
C G\end{array}$ & $\begin{array}{l}13.45 \\
13.37\end{array}$ & $>0.05$ & $\begin{array}{l}13.16 \\
13.13\end{array}$ & $>0.05$ & $\begin{array}{l}03.59 \\
03.52\end{array}$ & $>0.05$ & $\begin{array}{l}04.21 \\
04.35\end{array}$ & $>0.05$ & $\begin{array}{l}04.56 \\
04.46\end{array}$ & $>0.05$ & $\begin{array}{l}13.05 \\
13.07\end{array}$ & $>0.05$ \\
\hline \multicolumn{13}{|c|}{ Boys - amateur athletes (3000 meters) } \\
\hline $\begin{array}{l}E G \\
C G\end{array}$ & $\begin{array}{l}15.49 \\
15.38\end{array}$ & $>0.05$ & $\begin{array}{l}14.03 \\
14.55\end{array}$ & $<0.05$ & $\begin{array}{l}04.33 \\
04.29\end{array}$ & $>0.05$ & $\begin{array}{l}04.31 \\
04.59\end{array}$ & $<0.05$ & $\begin{array}{l}04.59 \\
05.27\end{array}$ & $<0.05$ & $\begin{array}{l}14.46 \\
14.53\end{array}$ & $>0.05$ \\
\hline \multicolumn{13}{|c|}{ Girls - professional athletes (2000 meters) } \\
\hline & $\begin{array}{c}2000 \\
\mathrm{~m}\end{array}$ & $P$ & $\begin{array}{c}2000 \\
\mathrm{~m}\end{array}$ & $P$ & $\begin{array}{c}0-650 \\
m\end{array}$ & $\mathrm{P}$ & $\begin{array}{c}650- \\
1300 \mathrm{~m}\end{array}$ & $\mathrm{P}$ & $\begin{array}{c}1300- \\
2000 \mathrm{~m}\end{array}$ & $P$ & $\begin{array}{c}2000 \\
\mathrm{~m}\end{array}$ & $P$ \\
\hline $\begin{array}{l}E G \\
C G\end{array}$ & $\begin{array}{l}10.54 \\
10.51 \\
\end{array}$ & $>0.05$ & $\begin{array}{l}09.51 \\
10.27 \\
\end{array}$ & $<0.05$ & $\begin{array}{l}03.16 \\
03.10 \\
\end{array}$ & $>0.05$ & $\begin{array}{l}03.22 \\
03.25 \\
\end{array}$ & $>0.05$ & $\begin{array}{l}03.13 \\
03.52 \\
\end{array}$ & $<0.05$ & $\begin{array}{l}10.22 \\
10.26 \\
\end{array}$ & $>0.05$ \\
\hline \multicolumn{13}{|c|}{ Girls - amateur athletes (2000 meters) } \\
\hline $\begin{array}{l}E G \\
C G\end{array}$ & $\begin{array}{l}12.19 \\
12.10\end{array}$ & $>0.05$ & $\begin{array}{l}10.19 \\
11.16\end{array}$ & $<0.05$ & $\begin{array}{l}03.12 \\
03.06\end{array}$ & $<0.05$ & $\begin{array}{l}03.18 \\
03.45\end{array}$ & $<0.05$ & $\begin{array}{l}03.49 \\
04.25\end{array}$ & $<0.05$ & $\begin{array}{l}10.58 \\
11.09\end{array}$ & $>0.05$ \\
\hline
\end{tabular}

${ }^{*} E G$ - the average result in the experimental group, $C G$ - the average result in the control group, $P$ - mathematical and statistical processing according to student T-criterion 
As can be seen from Table 1, as a result of the analysis of the results of the final middle-distance testing of professional athletes and amateur athletes of the experimental and control groups, it was revealed that the favourite running music had a significantly different effect at different stages of the study and by gender.

It should be especially noted that the results in middle-distance running in the preliminary testing were significantly identical between the experimental and control groups of athletes using musical accompaniment during the training process for each gender sample and qualification group. That proves the same physical readiness of the participants in the experiment before the start of the study. As a comparative study showed, the use of a specially prepared playlist at the time of passing the middle distance did not have a significant effect on the intermediate testing after a 3-month training process ( $>>0.05)$, which was not included in the table. This can be explained by the fact that the author's development in a given period of time cannot reliably affect the performance in aerobic maximum loads, namely, improving the results in such physical quality as endurance. One can also assume the following variant of the reliability of the result: almost a third of the experimental group did not fulfil the key condition of the study and their results were excluded from their experimental sample. However, it should be noted that positive shifts were recorded in both groups in favour of improving physical development, but they are not so statistically significant as mathematical processing showed $(p>0.05)$.

The recorded comparative results after a full cycle of training of athletes using musical accompaniment during the training process for 6 months allowed us to ascertain the positive dynamics among the respondents of the experimental group. In a comparative study of focus groups of boys and girls of amateur athletes, as well as girls of professional athletes, the significant significance of changing the results of the experimental group in favour of improving performance in running on the final test $(p<.05)$ was revealed. In turn, the mathematical-statistical comparison of the experimental and control groups for a sample of boys athletesprofessionals, revealed no significance in comparing the results $(p>0.05)$. The data obtained mean that more than a girl in a sample of athletes using musical accompaniment during the training process is exposed to the influence of the author's experiment in a group of amateur athletes.

From the analysis of the data obtained in the final control test in each of the three test segments, the significance of differences between the experimental and control groups in the first and third segments of the distance $(p<0.05)$ in the groups of boys and girls of amateur athletes was revealed. In the group of girls of professional athletes, only at the third mark $(p<0.05)$. However, in the middle of overcoming the distance, all sportsmen using musical accompaniment during the training process ran the second mark reliably the same $(p>0.05)$. This means that the implementation of the author's development can be effective only at the beginning and at the end of the athletics track in running.

A comparative study of focus groups on the final test two weeks after the implementation of the final test in middle-distance running, which was not accompanied by the introduction of the author's development, showed no significant differences $(p>0.05)$. Despite the fact that only two weeks have passed since the previous testing, which showed absolute reliability in the effectiveness of the study. However, this significant result in the advantage of the experimental group is only temporary, only for the period of control final testing. The high result is then worsened in the control testing without the use of musical accompaniment based on the author's condition to achieve the maximum emotional effect. At the maximum level, the athlete's distraction from the initial growing fatigue in the first third of the distance and further retention of the running pace necessary for victory is no longer achieved. Nevertheless, positive shifts were revealed in the control and experimental groups for all age and qualification samples $(p<0.05)$ in favour of improving endurance indicators. 
Amateur athletes participating in the experiment before the start of the study had a long-distance run result below the mark of the minimum (bronze) badge of the presidential test - the All-Russian physical-sports complex "Ready for Labor and Defense." However, after the implementation of the 6-week training process, their achievements corresponded to the level of the bronze and silver badges, and in some, unfortunately, a few cases, the maximum level - the golden insignia. From this we can conclude that the implementation of a systematic training process in running long and medium distances and the use of special musical accompaniment when fulfilling the author's conditions for its implementation during the control testing is significantly more effective. To a greater extent, to increase the result of amateur athletes in the control test for 2000 and 3000 meters.

As can be seen from Table 2, as a result of the analysis of the results of the experimental and control groups of athletes who do not use musical accompaniment during the training process, the following result was revealed in the preliminary, final and closing tests for middle distances. Specially selected musical accompaniment of the run had a statistically significant negative impact $(p<0.05)$ on the result in the run of boys amateur athletes, in particular on the third segment of the distance $(p<0.05)$. However, on this segment of the distance (1300-2000 meters), girls amateur athletes recorded a statistical result of the effectiveness of the author's development $(p<0.05)$. Nevertheless, a comprehensive analysis of control testing in girls' 2000 meters running did not allow us to determine the mathematical-statistical difference in overcoming the entire distance $(p<0.05)$ between the control and experimental groups (Table 2$)$.

Table 2. Results of control testing of athletes not using musical accompaniment during the training process.

\begin{tabular}{|c|c|c|c|c|c|c|c|c|c|c|c|c|}
\hline \multirow[b]{2}{*}{ Group } & \multicolumn{2}{|c|}{$\begin{array}{c}\text { Preliminary } \\
\text { testing }\end{array}$} & \multicolumn{7}{|c|}{ Final testing } & \multicolumn{2}{|c|}{$\begin{array}{l}\text { Closing } \\
\text { testing }\end{array}$} & \multirow[b]{2}{*}{$\mathrm{P}$} \\
\hline & $\begin{array}{c}3000 \\
\mathrm{~m}\end{array}$ & $P$ & $\begin{array}{c}3000 \\
m\end{array}$ & $P$ & $\begin{array}{c}0- \\
1000 \\
m\end{array}$ & $P$ & $\begin{array}{l}1000- \\
2000 \mathrm{~m}\end{array}$ & $P$ & $\begin{array}{c}2000- \\
3000 \\
m\end{array}$ & $P$ & $\begin{array}{c}3000 \\
m\end{array}$ & \\
\hline \multicolumn{13}{|c|}{ Boys - professional athletes ( 3000 meters) } \\
\hline $\begin{array}{l}E G \\
C G \\
\end{array}$ & $\begin{array}{l}13.32 \\
13.27 \\
\end{array}$ & $>0.05$ & $\begin{array}{l}13.01 \\
12.57 \\
\end{array}$ & $>0.05$ & $\begin{array}{l}03.47 \\
03.49 \\
\end{array}$ & $>0.05$ & $\begin{array}{l}04.15 \\
04.20 \\
\end{array}$ & $>0.05$ & $\begin{array}{l}04.59 \\
04.48 \\
\end{array}$ & $>0.05$ & $\begin{array}{l}12.58 \\
13.03 \\
\end{array}$ & $>0.05$ \\
\hline \multicolumn{13}{|c|}{ Boys - amateur athletes (3000 meters) } \\
\hline $\begin{array}{l}\text { EG } \\
\text { CG }\end{array}$ & $\begin{array}{l}15.33 \\
15.28 \\
\end{array}$ & $>0.05$ & $\begin{array}{l}14.39 \\
14.01\end{array}$ & $<0.05$ & $\begin{array}{l}04.47 \\
04.44\end{array}$ & $>0.05$ & $\begin{array}{l}04.54 \\
04.59\end{array}$ & $>0.05$ & $\begin{array}{l}04.58 \\
04.18\end{array}$ & $<0.05$ & $\begin{array}{l}14.14 \\
14.09\end{array}$ & $>0.05$ \\
\hline \multicolumn{13}{|c|}{ Girls - professional athletes (2000 meters) } \\
\hline & $\begin{array}{c}2000 \\
m\end{array}$ & $P$ & $\begin{array}{c}2000 \\
m\end{array}$ & $P$ & $\begin{array}{c}0-650 \\
\mathrm{~m}\end{array}$ & $P$ & $\begin{array}{c}650- \\
1300 \\
\mathrm{~m}\end{array}$ & $P$ & $\begin{array}{c}1300- \\
2000 \\
m\end{array}$ & $P$ & $\begin{array}{c}2000 \\
m\end{array}$ & $P$ \\
\hline $\begin{array}{l}E G \\
C G\end{array}$ & $\begin{array}{l}10.45 \\
10.39 \\
\end{array}$ & $>0.05$ & $\begin{array}{l}10.01 \\
09.54\end{array}$ & $>0.05$ & $\begin{array}{l}03.12 \\
03.03\end{array}$ & $>0.05$ & $\begin{array}{l}03.20 \\
03.21\end{array}$ & $>0.05$ & $\begin{array}{l}03.29 \\
03.30\end{array}$ & $>0.05$ & $\begin{array}{l}09.56 \\
09.49\end{array}$ & $>0.05$ \\
\hline \multicolumn{13}{|c|}{ Girls - amateur athletes (2000 meters) } \\
\hline $\begin{array}{l}E G \\
C G\end{array}$ & $\begin{array}{l}12.07 \\
11.58 \\
\end{array}$ & $>0.05$ & $\begin{array}{l}10.22 \\
10.16 \\
\end{array}$ & $>0.05$ & $\begin{array}{l}03.14 \\
02.59 \\
\end{array}$ & $<0.05$ & $\begin{array}{l}03.24 \\
03.03 \\
\end{array}$ & $>0.05$ & $\begin{array}{l}03.44 \\
04.14 \\
\end{array}$ & $<0.05$ & $\begin{array}{l}10.20 \\
10.41 \\
\end{array}$ & $>0.05$ \\
\hline
\end{tabular}

${ }^{*} E G$ - the average result in the experimental group, $C G$ - the average result in the control group, $P$ - mathematical and statistical processing according to student T-criterion

From the analysis of the data obtained by testing athletes who do not use musical accompaniment during the training process, it was proved during the experiment that the use of authoring in most focus groups does not significantly affect the increase or decrease of the result. In turn, the obtained reliable comparative result 
on the third segment of the distance in groups of amateur athletes may be random, due to a small sample of study participants in this category and requires further research work.

However, as in the above results on a sample of athletes who do not use musical accompaniment during the training process, it should be noted that shifts were recorded in both groups in favour of improving physical quality "endurance". Nevertheless, mathematical and statistical processing of the obtained numerical data of the experimental and control research groups at all stages of the experiment did not confirm the significance of differences in the comparative results $(p>0.05)$.

\section{DISCUSSION}

In general, the results of the study are consistent with the results of other studies on the positive impact of musical accompaniment on the effectiveness of the implementation of various physical exercises, in particular, running a distance. Thus, (Crust, 2004) experimentally proves that the effect of music during tests on muscle endurance can lead to a significant increase in endurance indicators, but the effect of music before the load did not affect the performance. In their study (Matesic \& Cromartie, 2002) showed that music has a noticeable effect on running results for both trained and unprepared runners. However, slight differences in heart rate and perceived load in the presence or absence of music were observed for untrained athletes. In the following studies (Baldari, 2010; Mohammadzadeh et al., 2008), on the contrary, experimentally confirms that music during exercise can improve this effect in more active athletes with however low sports qualifications. Scientists (Van Dyck \& Leman, 2016) found that music can have an ergogenic effect, namely, helping an athlete withstand more intense workouts, recover faster, avoid possible injuries and maintain health indicators. Thus, as statistically proved in our work, and comparing the data obtained from the studies indicated above, in order to obtain such positive effects, it is necessary to choose a sample of less trained athletes who are actively involved in physical education and sports. In some cases, the use of musical accompaniment can affect the short-term increase in the aerobic capacity of girls specializing in middle distances. However, this statement requires further research in the implementation of the experiment to introduce the author's development into the training process of professional athletes of various ages and qualifications and a larger sample of subjects.

Continuing the discussion, the authors of the article coincide with the opinion of several experts that classes with musical accompaniment do not equally positively affect students of different sexes. In their study (Anshel \& Marisi, 2013), it was proved that musical accompaniment affects more of male runners. The statement was confirmed by diagnostic methods for the PWC 170 test, in maintaining physical performance at 170 beats per minute. However, in our study, we prove the opposite: girls are more emotional and the effect on them was statistically more reliable. The concept of exercises for music is especially attractive for women: whether due to the physical culture that surrounds it, or the way to develop endurance or relaxation after exercise (Archana \& Mukilan, 2016). The reasons may be that the fairer sex is more prone to the effects of dance music and rhythmic movements to the music (Karageorghis, 2014). In turn, our observations during the experiment of girls of various qualification categories using musical accompaniment showed that the results obtained in effectiveness are related to the fact that they are more qualitative and responsible in choosing favourite melodies. Which ultimately reliably affected the more significant result of the introduction of music in the experimental group of girls, compared with a sample of boys.

The analysis of the positive results obtained in our study in the endurance run of medium intensity shows that it does not contradict the evidence of other scientists. Researchers experimentally substantiate the improvement of endurance indicators for perceived stress at low or medium intensity of exercises 
(Karageorghis, 2016). Music changes psychological and physiological arousal and therefore can be used to prepare for competitions or training as a stimulant or relaxation tool (Yamashita et al., 2006). In his study (Karageorghis, 2014), using treadmill running, found that motivational music led to a $15 \%$ increase in stamina to the point of voluntary exhaustion compared to the absence of music in the control state. Scientists (Kozina et al., 2018) experimentally prove the effectiveness of using specially developed training technology based on musical accompaniment in the development of general and special endurance of young athletes. Based on the diagnostic procedures for the Wingate test aimed at analysing aerobic lactate power, namely its peak power, capacity and degree of depletion, (Jarraya et al., 2012) experimentally proved the effectiveness in the training process of athletes involved in sports that require powerful and long-term muscle contractions of the lower extremities. In turn (Copeland \& Franks, 1991), experimentally proved in detail, comparing the load results at different time intervals and with various accompanying melodies, that soft, slow music reduces physiological and psychological excitement during submaximal exercises and increases endurance. According to a study (Lima-Silva et al., 2012), in athletes using musical accompaniment the average running speed for the first $1.5 \mathrm{~km}$ was statistically higher, but there were no significant differences during the last 1.5 $\mathrm{km}$ between athletes using music and no. In turn, the reliable data obtained in the experiment on the introduction of authoring in the run of professional and amateur athletes show great efficiency at the beginning of the track. This means that the impact of musical accompaniment has a greater effect on the athlete performing a moderate load than the maximum, since at the beginning of overcoming the average distance the athlete of any physical training does not run at maximum speed.

Continuing the discussion, it should be noted that the reliable results obtained in our study on the effectiveness of specially selected musical accompaniment $(p<0.05)$ just in the control test can be explained from various points of view: motivational, psychological and medical or physiological.

From the motivational aspect, our study was based on conceptual approaches to the selection of motivational music in the field of its use in performing control physical exercises in athletics. The degree to which listening to music causes changes in emotions and performance is determined by the level to which the selected music meets the motivational and emotional requirements, in other words, the person's metaemotional beliefs. The results of the study are consistent with an experiment confirming the effectiveness of the practical implementation of this concept of metaemotional beliefs on sports results in endurance running (Lane et al., 2011). Motivational music should be defined in terms of its effects: reducing the load perception, regulating arousal and improving affect. As shown in his study (Karageorghis, 2014), the musical accompaniment should only be with texts of heroism, fortitude relating to overcoming obstacles, and always under the rhythm of running (Hamburg \& Clair, 2003). During repeated exercises in endurance development, self-motivational music can significantly enhance the ergogenic effect, lower perceived stress ratings, increase energy efficiency, and ultimately lead to higher levels of endurance and power (Karageorghis \& Priest, 2012). Motivational music should consist of "catchy" melodies and inspirational lyrics associated with sporting efforts in a bright, uplifting harmonic structure (Lane et al., 2011). In their studies (Tenenbaum et al., 2004; Murrock \& Higgins, 2009), focuses on the fact that only running with specially selected melodies, music that captures a person's interest and associates physical activity with positive memories helps maintain physical activity under various aerobic loads.

In turn, our results complement the studies that prove the need to use special favourite, individual music for each participant in the experiment. So (Lanzillo et al., 2001) showed that only self-selected music enhances the perception of physical self-confidence, helps control the state of the body, and alleviates the borderline state of maximum fatigue. Some authors experimentally prove the influence of only specific music, for example, the results obtained (Anshel \& Marisi, 2013), which proved that the use of precisely synchronized 
music with physical movements has a positive effect on the ability to perform a task. However, the use of musical accompaniment imposed on the athlete to a lesser extent will positively affect the increase in sports results. As one of the options, it is necessary to conduct a preliminary survey of athletes about their favourite and motivational music tracks, which they find the most inspiring when walking at a running distance and implementing recovery and rest procedures (Terry \& Karageorghis, 2006). Thus, as statistically proved in our work, and comparing the obtained data from the studies indicated above, in order to get such positive effects, athletes should choose the right or differently favourite music passages and specific manipulations for running that are necessary to fully optimize the effect.

From a psychological point of view, studies (Potteiger et al., 2000) indicate that different types of music can act as an effective or passive distraction during exercise and are associated with lower perceived loads. During submaximal exercises, music can narrow your attention, and this, in turn, distracts the mind from feeling tired. This distracting method, known as dissociation, namely reducing the perception of effort on the treadmill to $12 \%$. This effect persists for low moderate modes of exercise intensity, and at high intensity, the perception of fatigue overlaps the influence of music, because psychological and physiological feedback, such as breathing rate and accumulation of lactic acid in the muscles, prevail in the attention processes (Karageorghis, 2014). In turn, research (Brown, 1979) proves that the main advantages of music are improved mental performance through mood, arousal, increased labour productivity, dissociation from feelings of pain and fatigue, as protective mental mechanisms, through the "separation" of oneself from one's unpleasant experiences. In unison (Terry \& Karageorghis, 2006) experimentally substantiate the positive influence of music through evoking pleasant historical images among students, lower internal assessments of perceived load, especially during aerobic training. In this aspect, it is contemplated that an immersive medium caused by audio-visual stimuli helps control movements and alleviate symptoms associated with fatigue during exercise. Based on the study of pleasant and unpleasant audio-visual stimuli for perception and psychophysiological reactions during moderate-intensity exercises (Barreto-Silva et al., 2018), a significant decrease in psycho-physical stress caused by physical activity was proved. Motivational music evokes a "distraction effect" through a psychophysiological response in which people visualize themselves in the context of pleasant past or future moments in life, as if the situation were real and forget about the load performed while running (Yamashita et al., 2006). Based on the elements of rhythm, melody, tone and harmony, music produces psychological reactions within a person as it passes through the auditory cortex of the brain, which processes music. This processing takes place in the limbic system, which is known as the centre of emotions, sensations and feelings, and a person's reaction to music occurs mainly in the right hemisphere of the brain, which is involved in intuitive and creative methods of information processing (Tramo, 2001).

From a medical or physiological point of view, the results of studies on the effectiveness of musical accompaniment suggest that it is experimentally proved in work (Szmedra, 1998) that music exerts a psychobiological effect on the trainee, as demonstrated by changes in perceived effort, lactate and norepinephrine. Music allows runners to relax, reducing muscle tension, thereby increasing blood flow and clearance of lactate, while also reducing lactate production in working muscles. In turn, (Karageorghis, 2014) obtained results that showed that music with an average rhythm was more reliably effective at $70 \%$, since this rhythm of music is closer to the rhythm of the heartbeat. However, experimental studies (Matesic \& Cromartie, 2002) showed that there was no significant difference in the influence of music on factors such as pitch, heartbeat, and understanding of pressure. Based on clinical practice and research, some scientists have proven the healing effect of listening to music while they perform physical exercises, in particular, longterm aerobic physical activity (Clark et al., 2015). The music used by the runner, as shown by experimental studies (Bigliassi et al., 2019), redistributes attention, enhances beta waves, leads to more dissociative 
thoughts, causes more positive affective reactions and a more positive emotional state. In which athletes are more likely to separate from internal sensory signals and focus on a positive state that enhances arousal and increases perceived pleasure from physical activity. Scientists substantiate the assumption that the release of dopamine in the striatal system, caused by pleasant songs, is involved in the autonomic regulation of the heart. Musical auditory stimulation during running, in turn, significantly affects heart rate variability through the neural mechanism (Valenti et al., 2012). It is assumed that preferred music synchronizes with active physical activity and increases the activity of the sympathetic nerve (Urakawa \& Yokoyama, 2005). The use of favourable music during a long run activates the limbic system and the body works more economically due to the additional release of endorphins. Distracting the individual perception of the load through peripheral signals of muscle discomfort and fatigue, the central signals of changes in heart rate and respiratory rate mediated by the autonomic nervous system, music allows them to minimize peripheral and central signs of discomfort (Szmedra \& Bacharach, 1998; Yamashita et al., 2006).

Ultimately, the results obtained in the study, on the one hand, reveal the depth to a holistic solution to the problem, on the other, they plan further promising studies. So (Elliott et al., 2004) began a study on the effect of motivational music during a 12-minute cycle of an ergometer at a constant speed, but with different force pressures on the pedals. In turn, the study participants, despite the aggravation of conditions, continued to exercise loads of music at the same pace. It should be noted that the advantages of music are obvious from the point of view of reducing the perception of physical activity in distance running in mountain running or in various heavier conditions (snow, sand, etc.). What will be the object of our further research on this issue?

\section{CONCLUSIONS}

Thus, the efficiency of using musical accompaniment to develop such a physical quality as endurance, experimentally tested in our study, can be justified not only practically, but also theoretically from an analysis of this kind of scientific work.

Our experimental work complements the research on the positive evidence of the influence of music on performance in running. Especially those studies that statistically prove the special significance of special motivating music in moderate loads during overcoming the medium or long distance. The comparative results obtained in the study in gender and level aspects, that musical accompaniment has a greater impact on girls and amateur athletes, are also consistent with the experimental opinion of several scientists. However, the practical significance and novelty of the work lies in the fact that the efficiency of playing music while running will be effective in the control test, if the key condition is clearly taken into account. Namely, the achievement of the maximum emotional effect from listening to the "long-awaited month" playlist, designed to arouse pleasant feelings and historical images, and to distract the athlete from the initial growing fatigue in the first third of the distance and in the future to maintain the running pace necessary for victory.

The proposed provisions and conclusions create the prerequisites for further studying the phenomenon of the realization of musical sportification of physical education and sports activities with various contingents of runners in methodological, substantive and organizational aspects. The presented practical experience in overcoming the control average distance in running for 2000 and 3000 meters for endurance testing can be used in the professional activity of trainers and teachers of physical education of various physical education and sports organizations in the process of training and competitive activity. 


\section{CONFLICT OF INTEREST}

There were no conflicts of interest.

\section{REFERENCES}

Anshel, M.H., \& Marisi D.Q. (2013). Effect of Music and Rhythm on Physical Performance, Research Quarterly. American Alliance for Health, Physical Education and Recreation, 49(2), 109-113. https://doi.org/10.1080/10671315.1978.10615514

Archana, R., \& Mukilan, R. (2016). Beneficial Effect of Preferential Music on Exercise Induced Changes in Heart Rate Variability. J Clin Diagn Res.;10(5), 09-11. https://doi.org/10.7860/jcdr/2016/18320.7740

Atan, T. (2013). Effect of music on anaerobic exercise performance. Biol Sport, 30(1), 35-39. https://doi.org/10.5604/20831862.1029819

Baldari, C., Macone, D., Bonavolontà, V., \& Guidetti, L. (2010). Effects of music during exercise in different training status. J Sports Med Phys Fitness, 50(3), 281-7.

Barreto-Silva, V., Bigliassi, M., Chierotti, P., \& Altimari, L.R. (2018) Psychophysiological effects of audiovisual stimuli during cycle exercise. European Journal of Sport Science, 18(4), 560-568, https://doi.org/10.1080/17461391.2018.1439534

Bigliassi, M., Karageorghis, C.I., Hoy, G.K., \& Layne, G.S. (2019). The Way You Make Me Feel: Psychological and cerebral responses to music during real-life physical activity. Psychology of Sport and Exercise. 41, 211-217. https://doi.org/10.1016/j.psychsport.2018.01.010

Brown, P. (1979). An enquiry into the origins and nature of tempo behaviour: II. Experimental work. Psychology of Music, 9, 32-43.

Clark, I.N., Baker, F.A. \& Taylor, N.F. (2015). The modulating effects of music listening on health-related exercise and physical activity in adults: a systematic review and narrative synthesis. Nordic Journal of Music Therapy, 25(1), 76-104. https://doi.org/10.1080/08098131.2015.1008558

Copeland, B.L., \& Franks, B.D. (1991). Effects of types and intensities of background music on treadmill endurance. J Sports Med Phys Fitness, 31(1), 100-3.

Crust, L. (2004). Carry-over effects of music in an isometric muscular endurance task. Percept. Motor Skills, 98, 985-991. https://doi.org/10.2466/pms.98.3.985-991

Dyrlund, A.K., \& Wininger, S.R. (2008). The effects of music preference and exercise intensity on psychological variables. Journal of Music Therapy, 45, 114-134. https://doi.org/10.1093/jmt/45.2.114

Elliott, D., Carr, S., \& Savage, D. (2004). Effects of motivational music on work output and affective responses during sub-maximal cycling of a standardized perceived intensity. Journal of Sport Behavior, 27, 134-147.

Ghobadi, M.R. (2018). Impact music on some of physical readiness factors in exercised and unexercised Girl student. International Journal of Applied Exercise Physiology, 8(1), 35-41. https://doi.org/10.30472/ijaep.v8i1.354

Hamburg, J, \& Clair, A.A. (2003). The effects of a movement with music program and measures of balance and gait speed in healthy older adults. Journal of Music Therapy, 40(3), 212-226. https://doi.org/10.1093/jmt/40.3.212

Jarraya, M., Chtourou, H., Aloui, A., Hammouda, O., Chamari, K., Chaouachi, A. \& Souissi, N. (2012). The effects of music on high-intensity short-term exercise in well trained athletes. Asian journal of sports medicine, 3(4), 233-238. https://doi.org/10.5812/asjsm.34543

Karageorghis, C.I. (2016). Applying Music in Exercise and Sport. Brunel University London. Human Kinetics, 264. 
Karageorghis, C.I., Drew, K.M., \& Terry, P.C. (1996). Effects of pretest stimulative and sedative music on grip strength. Perceptual and Motor Skills, 83, 1347-1352. https://doi.org/10.2466/pms.1996.83.3f.1347

Karageorghis, C.I., \& Priest, D.L. (2012). Music in the exercise domain: a review and synthesis (Part I). Int Rev Sport Exerc Psychol, 5(1), 44-66.

Karageorghis, C.I., Terry, P.C., \& Lane, A.M. (1999). Development and validation of an instrument to assess the motivational qualities of music in exercise and sport: The Brunel Music Rating Inventory. Journal of Sports Sciences, 17, 713-724. https://doi.org/10.1080/026404199365579

Karageorghis, C.I. (2014). Run to the Beat: Sport and music for the masses. Sport in Society, 16, 443447. https://doi.org/10.1080/17430437.2013.796619

Kozina, Zh.L., Kalinicenko, V.E., Cretu, M., Osiptsov, A.V., Kudryavtsev, M.D., Polishchuk, S.B., Ilnickaya, A.S., \& Minenok, A.O. (2018). Influence of music on the level of physical ftness of the students practicing rugby (rugby players students). Physical education of students, 22(3), 120-126. https://doi.org/10.15561/20755279.2018.0302

Lane, A.M., Davis, P.A., \& Devonport, T.J. (2011). Effects of music interventions on emotional states and running performance. J Sports Sci Med, 10, 400-407.

Lanzillo, J.J., Burke, K.L., Joyner, A.B., \& Hardy, C.J. (2001). The effects of music on the intensity and direction of pre-competitive cognitive and somatic state anxiety and state self-confidence in collegiate athletes. International Sports Journal, 5, 101-110.

Lima-Silva, A.E., Silva-Cavalcante, M.D., Pires, F.O., Bertuzzi, R., Oliveira, R. S., \& Bishop, D. (2012). Listening to music in the first, but not the last $1.5 \mathrm{~km}$ of a $5-\mathrm{km}$ running trial alters pacing strategy and improves performance. Int J Sports Med, 33(10), 813-8. https://doi.org/10.1055/s-0032-1311581

Matesic, B.C., \& Cromartie, F. (2002). Effects music has on lap pace, heart rate, and perceived exertion rate during a 20-minute self-paced run. The sport journal, 5(1).

Mohammadzadeh, H., Tartibiyan, B., \& Ahmadi, A. (2008). The effects of music on the perceived exertion rate and performance of trained and untrained individuals during progressive exercise. Facta Univ Phys Educ Sport, 6, 67-74.

Murrock, C.J., \& Higgins, P.A. (2009). The theory of music, mood and movement to improve health outcomes. J Adv Nurs, 65(10), 2249-57. https://doi.org/10.1111/j.1365-2648.2009.05108.x

Nagovitsyn, R.S., Chigovskaya-Nazarova, Y.A., Miroshnichenko, A.A., \& Senator, S.Y. (2018). The realization of the system programme "Health saving education" in the pedagogical university. $\begin{array}{llll}\text { European Journal of Contemporary } & \text { Education, 1(7), }\end{array}$ https://doi.org/10.13187/ejced.2018.1.137

Nagovitsyn, R.S., Rassolova, E.A., Sokolnikova, E.I., Senator, S.Y., \& Torbina, I.I. (2015). Technology of system development of physical qualities of young people with regard to mobile learning. Teoriya i Praktika Fizicheskoy Kultury, 11, 100-102.

Potteiger, J.A, Schroeder, J.M, \& Goffi, K.L. (2000). Influence of music on ratings of perceived exertion during 20 minutes of moderate intensity exercise. Percept. Motor Skills, 91, 848-854. https://doi.org/10.2466/pms.91.7.848-854

Szmedra, L., \& Bacharach, D.W. (1998). Effect of music on perceived exertion, plasma lactate, norepinephrine and cardiovascular hemodynamics during treadmill running. Int J Sports Med, 19(1), 32-7. https://doi.org/10.1055/s-2007-971876

Tenenbaum, G., Lidor, R., Lavyan, N., Morrow, K., Tonnel, S., \& Gershgoren, A. (2004). The effect of music type on running perseverance and coping with effort sensations. Psychology of Sport and Exercise, 5, 89-109. https://doi.org/10.1016/s1469-0292(02)00041-9

Terry, P.C., \& Karageorghis, C.I. (2006). Psychophysical effects of music in sport and exercise: An update on theory, research and application. In M. Katsikitis (Ed.), Psychology bridging the Tasman: 
Science, culture and practice - Proceedings of the 2006 Joint Conference of the Australian Psychological Society and the New Zealand Psychological Society, 415-419.

Thaut, M.H., Kenyon, G.P., Schauer, M.L., \& Mclntosh, G.C. (1999). Rhythmicity and brain function: implications for therapy of movement disorders. IEEE Engineering in Medicine and Biology, 18, 101108. https://doi.org/10.1109/51.752991

Tramo, M.J. (2001). Biology and music: music of the hemispheres. Science, 291(5501), 54-56. https://doi.org/10.1126/science.10.1126/science.1056899

Urakawa, K., \& Yokoyama, K. (2005). Music can enhance exercise-induced sympathetic dominancy assessed by heart rate variability. Tohoku J Exp Med, 206(3), 213-8. https://doi.org/10.1620/tiem.206.213

Valenti, V.E., Guida, H.L., Frizzo, A.C., Cardoso, A.C., Vanderlei, L.C., \& Abreu, L.C. (2012). Auditory stimulation and cardiac autonomic regulation. Clinics (Sao Paulo), 67(8), 955-8. https://doi.org/10.6061/clinics/2012(08)16

Van Dyck, E., \& Leman, M. (2016). Ergogenic Effect of Music during Running Performance. Ann Sports Med Res, 3(6), 1082.

Yamashita, S., Twai, K., Aktmoto, T., Sugawara, J., \& Kono, I. (2006). Effects of music during exercise on RPE, heart rate and the autonomic nervous system. J Sports Med Phys Fitness, 46, 425-430.

\section{@) $\Theta \Theta \Theta$}

This work is licensed under a Attribution-NonCommercial-NoDerivatives 4.0 International (CC BY-NC-ND 4.0). 